\title{
SEVERITY OF SNAKE BITE WITH EARLY PREDICTORS OF THROMBOCYTOPENIA AND ALBUMINURIA IN ACUTE KIDNEY INJURY
}

\section{Dr. Ashmitha Padma*}

${ }^{*}$ Corresponding Author

\section{Dr. Pramila Devi}

ABSTRACT Snakebites are very common public health problems which is caused by venomous arthropods effecting many organs and causing fatal emergencies. Snakebite can cause direct or indirect nephro toxicity, especially hematotoxic snakebites. It is important to know the early predictors of acute kidney injury so as to prevent the complications early.

Methods: This is a prospective case series study conducted at S. Nijalingappa Medical College and Hangal Shri Kumareshwar Hospital and Research center, Bagalkot from June 2018 to June 2019.

Results: Total of 51 patients were included in this study who satisfied the inclusion and exclusion criteria. It was found that 35 patients had thrombocytopenia with $\mathrm{p}$ value of $<0.002$, which was highly significant. Serum creatinine was found to be more than $1.2 \mathrm{mg} / \mathrm{dl}$ in 35 patients and the p value was $<0.002$ which was highly significant and urine albumin was also found to be more which p avalue was $<0.001$. among the study subjects $70 \%$ of them were found to have thrombocytopenia with albuminuria and increase in serum creatinine.

\section{KEYWORDS : Serum Creatinine, Thrombocytopenia, Urine Albumin.}

\section{INTRODUCTION}

Snake bite is a preventable health hazard. It accounts for 125 175 deaths per day in India and annual deaths are around 45,000 . Snake bites are more in farmers as they work in fields bare footed unintentionally in a handful of foliage rolling over the snake while asleep. Males are more affected than females and lower limbs are the most common sites ${ }^{1}$.

Acute kidney injury is common manifestation of hematotoxic snake bites. Factors contributing to acute kidney injury are direct cytotoxicity, bleeding, hypotension, Intravascular hemolysis, DIC, microangiopathic haemolytic anemia 6 .

Renal histology in pathology of acute kidney injury in snake bite is mostly acute tubular or cortical necrosis. In snake bite there may be bilateral diffuse or patchy cortical necrosis. It is more common in Indian patients. The prominent feature in these patients is the presence of fibrin thrombi at renal cortex.

Objective:

- To correlate the association of albuminuria and acute kidney injury

- To correlate the association of thrombocytopenia and acute kidney injury

\section{Methodology}

The information for the study was collected from patients admitted to S. Nijalingappa Medical College and Hangal Shri Kumareshwar Hospital and Research center, Bagalkot from June 2018 to June 2019. Information was collected through prepared profoma from each patient. Qualifying patients have undergone detailed history taking, clinical examination and laboratory investigations.

\section{Inclusion Criteria}

- Patients with hematotoxic snakebite

\section{Exclusion Criteria}

- Known hypertension and on treatment

- Known diabetic and on treatment

- Chronic history of NSAID intake

- Past history of renal disease

- Previous ultrasonogram evidence of chronic kidney disease

\section{Sample Size}

This was calculated by using OpenEpi, Version 2.0 open source calculator SSMean software at 95\% confident level.

\section{Sampling}

This is a case series study. It was done by simple SD Mean table. Hence 51 cases were included.

\section{RESULTS}

Correlation Of Thrombocytopenia With Acute Kidney Injury:

Table No.l Shows Correlation Between Thrombocytopenia Among Patients With AKI And Without AKI

\begin{tabular}{|l|l|l|l|}
\hline Platelet count & $\begin{array}{l}\text { Patients } \\
\text { with AKI }\end{array}$ & $\begin{array}{l}\text { Patients } \\
\text { without } \\
\text { AKI }\end{array}$ & Total \\
\hline$<1,50,000$ & 35 & 12 & 26 \\
\hline $1,50,000-4,00,000$ cells/cumm & 0 & 4 & 25 \\
\hline Total & 35 & 16 & 51 \\
\hline Chi Square Test P<0.002, Highly Sig \\
\hline
\end{tabular}

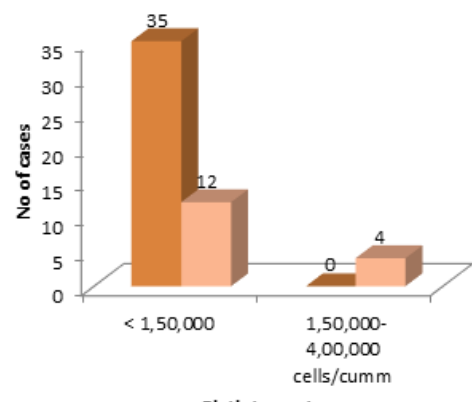

Patients with AKI Inatients without AKI

Platlet count

Figure No.1 Bar Chart Showing The Correlation Among Patients With AKI And Without AKI

Correlation Of Serum Creatinine With Acute Kidney Injury: Table No.2 Correlation Between S. Creatinine With AKI

\begin{tabular}{|l|l|l|l|}
\hline Serum Creatinine & $\begin{array}{l}\text { Patients } \\
\text { with AKI }\end{array}$ & $\begin{array}{l}\text { Patients } \\
\text { without AKI }\end{array}$ & Total \\
\hline $0.7-1.2 \mathrm{mg} / \mathrm{dl}$ & 0 & 4 & 4 \\
\hline$>1.2$ & 35 & 12 & 47 \\
\hline
\end{tabular}




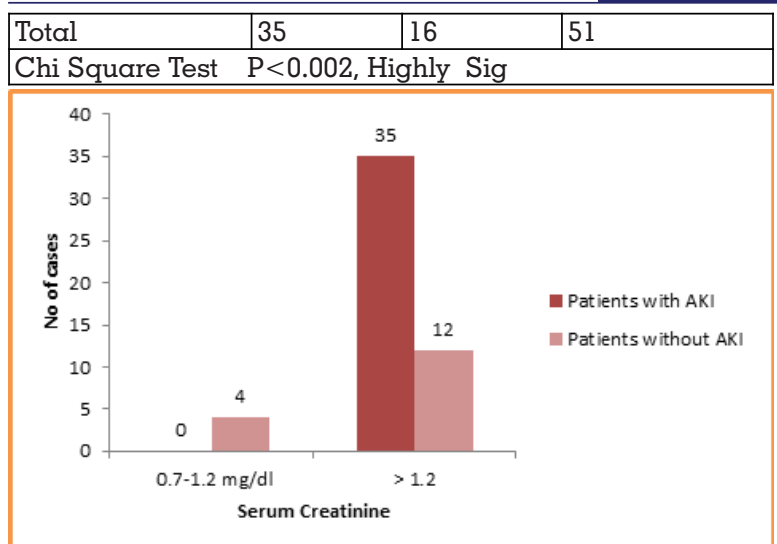

Figure No.2 Showing Correlation Between S. Creatine And AKI

Correlation Of Urine Albiminuria With Acute Kidney Injury:

Table No.3 Shows The Correlation Between Urine Albuminuria And AKI

\begin{tabular}{|l|l|l|l|}
\hline U. ALB & Patients with AKI & Patients without AKI Total \\
\hline
\end{tabular}

\begin{tabular}{|l|l|l|l|}
\hline Traces & 0 & 5 & 5 \\
\hline $1+$ & 11 & 7 & 18 \\
\hline $2+$ & 24 & 2 & 26 \\
\hline Nil & 0 & 2 & 2 \\
\hline Total & 35 & 16 & 51 \\
\hline Chi Square Test P<0.00l, Highly Sig \\
\hline
\end{tabular}

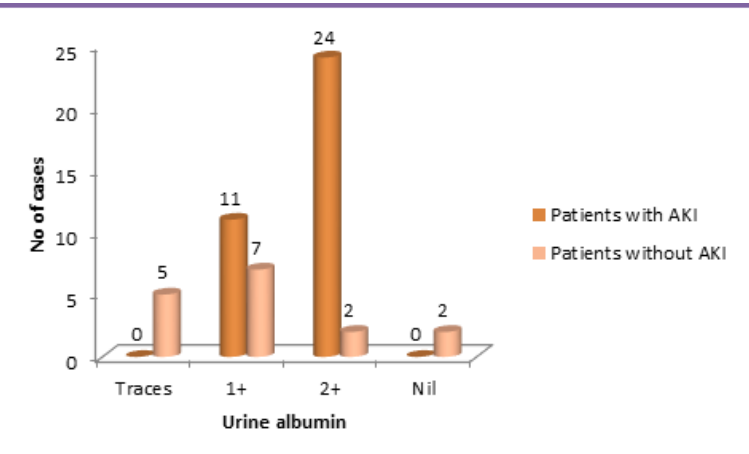

Figure No. 3 Bar Chart Showing The Correlation Between Urine Albuminuria Among Patient With AKI And Patients Without AKI.

\section{DISCUSSION}

In this study total of 51 patients were included who satisfied the inclusion and exclusion criteria. Among the patients studied were in the age group of 20-50 years, among them 35 patients were found to develop Acute Kidney Injury with the mean age being $30.4+/-12.0$ years and remaining 16 patients did not develop acute kidney injury with the mean age being $35.6+/-14.9$ years. Maximum patients who developed Acute Kidney Injury were between the age group of 20-29 years. Among the patients studied 25 of them were females among them 17 had developed acute kidney injury and remaining 8 patients did not develop acute kidney injury. In the patients included in the study, 26 were males among them 18 developed acute kidney injury and remaining 8 of them did not develop acute kidney injury.

Among the patients studied in this study, patients with acute kidney injury had the heart rate mean of $80+/-5.7$ per minute and $75+/-3.5$ per minute in the patients without acute kidney injury. In the patients studied mean systolic blood pressure was $119.4+/-10.8 \mathrm{~mm} \mathrm{Hg}$ in the patients with acute kidney injury and mean of $122.8+/-12.8 \mathrm{~mm} \mathrm{Hg}$ in the patients without acute kidney injury. Diastolic blood pressure mean was 75.3 $+/-5.8 \mathrm{~mm} \mathrm{Hg}$ in patients with acute kidney injury and mean of
$76.0+/-5.8 \mathrm{~mm} \mathrm{Hg}$ in patients without acute kidney injury. The vital parameters were not significant except for heart rate among the patients with acute kidney injury.

Among the patients included in the study, the laboratory parameters included were hemoglobin, total white blood count, platelet count, serum. creatinine, serum sodium, serum potassium, blood urea, urine albumin. In the study subjects it was noticed that the mean hemoglobin was $11.4+/-1.5$ in subjects who developed acute kidney injury and $11.8+/-2.0$ in subjects who did not develop acute kidney injury.The total white blood cell count was of mean 10671.4+/-2958.7 in subjects who developed acute kidney injury and mean of $11387.5+/-3812.1$ in subjects who did not develop acute kidney injury. Platelet count was mean of $87237+/-15982.7$ in subjects who developed acute kidney injury and mean of $132875+/-95162.5$ in subjects who did not develop acute kidney injury. Serum creatinine was found to be mean of $2.2+/-0.6$ in subjects with acute kidney injury and 1.4+/-.04 mean in subjects who did not develop acute kidney injury. Serum sodium was found to be mean of $143.4+/-8.3$ in subjects with acute kidney injury and mean of $140.4+/-2.7$ in subject without acute kidney injury. Serum potassium was noted to be mean of $4.1+/-0.5$ in subjects with acute kidney injury and mean of $4.1+/-0.5$ in subjects without acute kidney injury. Blood urea was mean of $29.3+/-5.1$ in subjects with acute kidney injury and mean of $25.1+/-3.9$ in subjects without acute kidney injury.

Among the subjects studied, it was noted that 35 subjects who developed acute kidney injury and 12 subjects without acute kidney injury had platelet count less than $1,50,000$ cells/ cumm as shown in figure no.l. Among the subjects studied, 35 subjects with acute kidney injury and 12 subjects without acute kidney injury had serum creatinine more than $1.2 \mathrm{mg} / \mathrm{dl}$. And only 4 subjects without Acute Kidney Injury had serum creatinine between $0.7-1.2 \mathrm{mg} / \mathrm{dl}$, as explained in figure no.2. In the study subjects only 5 subjects without acute kidney injury had trace urine albuminuria, 11 subjects with acute kidney injury and 7 without acute kidney injury had urine albuminuria of $1+$, and 24 subjects with acute kidney injury and 2 subject without acute kidney injury had urine albuminuria $2+$, ref- figure no. 3 .

In this study it was found that Chi Square test was highly significant with $\mathrm{P}$ value $<0.002$ among the patients with Thrombocytopenia. Among the study subjects $\mathrm{P}$ value for Serum creatinine was also highly significant with $P$ value $<0.002$. In this study the $\mathrm{P}$ value for Urine Albuminuria was also highly significant by $<0.001$.

In the study subjects included were given Antisnake venom as treatment. Serum creatinine was repeated after 48 hours and was found to be improving. None of the patients were in sepsis, hypotension or on dialysis.

Other studies conducted by Chugh KS et $\alpha^{6}{ }^{6}$, Pinha F M et $\mathrm{al}^{7}$, Naqvi R et $\mathrm{al}^{8}$, and Mukhopadhyay $\mathrm{P}$ et al ${ }^{9}$, found that the mean age in snake bite poisoing is varying from 24 years to 43 years. Our study also has the mean age of patients with snake bite fall under the similar category to other studies.

Studies conducted by Athappan G et $a{ }^{10}{ }^{10}$, Krishnamurthy S et $\mathrm{al}^{11}$, Pinha F M et al ${ }^{7}$, Naqvi R et $\mathrm{al}^{8}$, and Mukhopadhyay P et al ${ }^{9}$, found that similar inference that the snake bite is higher in males than females. The ratio of male to female in snake bite ranges from 4:1 in the study conducted by Ahuja and Singh et $\mathrm{al}^{12}$. Our study is alsi in concordance with the other studies in this aspect. Similarly, in the studies conducted by N. Suchitra et $\alpha l^{13}$ and G. Ali et al ${ }^{14}$ the bleeding tendencies observed was significantly associated with the development of Acute Kidney Injury. 


\begin{tabular}{|l|l|l|}
\hline Study & Thrombocytopenia & Albuminuria \\
\hline Sanjay et al & $47.7 \%$ & $91 \%$ \\
\hline Tushar et al & $50.7 \%$ & $52.29 \%$ \\
\hline Ganesh Athappan et al & $49.7 \%$ & $45.3 \%$ \\
\hline Ramaswamy S et al & $85.7 \%$ & $80 \%$ \\
\hline Our study & $70 \%$ & $71.3 \%$ \\
\hline
\end{tabular}

The major limitations in this study was that the other factors were not considered that could possibly affect the development of Acute Kidney injury like time to hospital, dose of ASV administered and development of hypotension. Nevertheless this study gives direct evidence that the albuminuria and thrombocytopenia in the setting of snake bite could predict the Acute Kidney Injury.

Majority of snake bites are prevented by wearing bumboats and also using the torch during the night time. Snake bites can be prevented by wearing long pants, also by not disturbing the snake. Patients were also educated regarding tying the tourniquet and taking the treatment and not going for any alternative medicines.

\section{CONCLUSION:}

In the patients with snake bite,

- Presence of thrombocytopenia can predict the occurrence of Acute Kidney Injury at the earlier stage

- Presence of albuminuria can predict the occurrence of Acute Kidney Injury at the earlier stage.

- Albuminuira and thrombocytopenia are associated with development of Acute Kidney Injury.

\section{REFERENCES}

1. Deutschman, Clifford S; Neligan, Patrick J. (2010). Evidence based practice of Critical Care. Elsevier Health Sciences. ISBN 1416054766. Retrived 2015-04-30.

2. Interpreting Signs and Symptoms. Lippincott Williams and Wilkins.2007.

3. Bawaskar HS, Bawaskar PH, Punde DP, Inamdar MK, Dongare RB, Bhote Rr J Assoc Physicians India.2008 feb; 56: pp. 88-95.

4. Brunda g, Sashidhar RB. Epidemiological profile of snake bite cases from Andhra Pradesh using immunoanalytical approach.Indian J Med Res. 125, 2007,pp. 661-668.

5. Viramani SK, Dutt OP. A profile of snake bite poisoning in Jammu region. J Indian med assoc. 85, 1987,pp.132-34.

6. K. S. Chigh, B. K. Aikat, B.K. Sharma et al. Acute Renal failure following snake bite. Am. J. Trop. Med. Hyg., 224(4), 1975, pp. 692-697.

7. Pinho FM, Yu L, Burdmann EA. Snakebite induced Acute Kidney Injury in Latin America. SeminNephrol. 28(4),2008,pp. 354-362.

8. Naqvi R. Snake bite induced Acute Kidney Injury. J Coll Physicians Surg Pak. 26(6),2016,pp. 517-520.

9. P. Mukhopadhyay, R Mishra, D Mukherjee et al. Snake bite medicated acute kidney injury, prognostic predictors,oxidative and carbonyl stress: A prospective study. Indian J nephrol.26(6),2016,pp,427-433.

10. Ganeh Athappan et al. Acute renal failure in Snake Envenomation: A Large Prospective Study. Saudi J KidneyDisTranspl 19(3),2008,pp 404-410.

11. Krishnamurthy S, Narayanan P, Prabha S et al. Clinical profile of acute kidney injury in a pediatric intensive care unit from Southern India: A prospective observational study. Indian J crit Care med. 17(4),2013,pp, 207-213.

12. Bhat RN. Viperine snake poisoning in Jammu. J Indian med Assoc. 1974,63,pp.383-92. 